
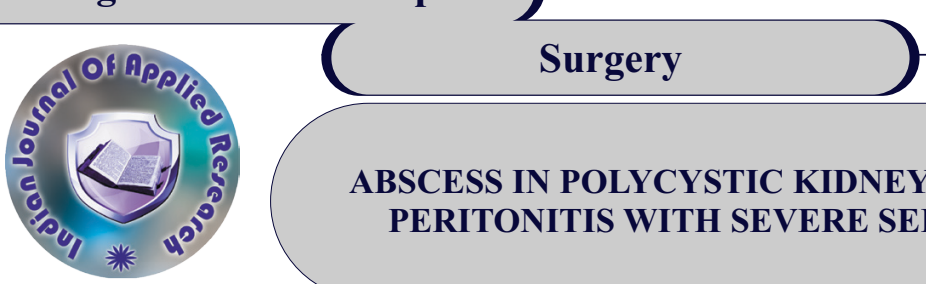

\title{
ABSCESS IN POLYCYSTIC KIDNEY PRESENTED AS GENERALISED PERITONITIS WITH SEVERE SEPSIS : A RARE CASE REPORT.
}

\section{Dr. Sandip. E.} Jadhav

Professor ,Department Of General Surgery, SKNMC, Pune

\section{Dr. Swapnilkumar.}

B. Nakhale*

PG Resident, Department Of General Surgery, SKNMC, Pune *Corresponding Author

\section{Dr. Rajesh Sonsale Associate Professor, Department Of General Surgery, SKNMC ,Pune}

ABSTRACT Recurrent Upper Urinary Tract Infections have been reported to be frequent in patients with autosomal dominant polycystic kidney disease and often difficult to treat. Female Preference and Enteric organism predominance suggests that these renal infections are acquired to retrograde from lower urinary tract. We encountered a rare of bilateral polycystic kidney with abscess in right kidney presented as a generalised Peritonitis with severe sepsis with multi organ failure. The Patient is successfully managed with Surgery followed by Prolonged supportive care at intensive care unit.

\section{KEYWORDS :}

\section{INTRODUCTION}

Multiple renal cysts occur commonly in autosomal dominant Polycystic kidney disease and are generally considered to have little clinical significance. ${ }^{1,2}$. There are several complications that can develop with ADPKD including abdominal pain, renal masses, kidney stones, hematuria, hypertension, urinary tract infections, manifestations of stroke secondary to cerebral hemorrhage of ruptured aneurysms, hepatic cysts, cardiovascular system manifestations, and inguinal, abdominal, and umbilical hernias, as well as colonic diverticula ${ }^{2-5 .}$ Infection of a cyst within a polycystic kidney is a serious complication of Autosomal Dominant Polycystic Kidney Disease, potentially leading to abscess, sepsis, and death. Female preference and enteric organism predominance suggest that these renal infections are acquired as retrograde infection from the urinary bladder ${ }^{6}$ Infection within Cyst is very rare. Retroperitoneal sepsis and peritonitis due to infected cyst are very unusual. To our knowledge, early diagnosis and surgical treatment are crucial to prevent lethal complications.

\section{Case Report}

A 40-year-old female known to have bilateral polycystic kidneys was admitted to emergency room with severe abdominal pain since 5-6 days, burning micturition since 8-10 days, loss of appetite since 5-6 days, high-grade fever $(38.7$ C) since 2 days. Known case of hypertension since 15 years .

History of Polycystic kidney in family, in her 3 female and one male child, Her brother expired due to renal failure with Polycystic Kidney disease 2 years ago. No previous operative history.

General examination reveals early septicemia with tachycardia, and hypotension. Per Abdomen examination revealed generalized abdominal distension with severe right lumbar and right hypochondriac tenderness. Blood investigation were done, Hemoglobin was $7 \mathrm{~g} / \mathrm{dl}$, White blood cell count was $28000 / \mathrm{mm} 3$, with $92 \%$ neutrophil, Blood Urea was $96 \mathrm{mg} / \mathrm{dl}$ and Creatinine level was 4.2 $\mathrm{mg} / \mathrm{dl}$, Arterial blood gas showed mild acidosis with $\mathrm{pH} 7.12$ and lactate of $5.4 \mathrm{mmol} / \mathrm{dL}$.

Provisional diagnosis of Peritonitis With Right Pyonephrosis In A Known Case Of Polycystic Kidney Disease was made, and the patient was resuscitated. Microscopic examination of urine suggestive of 40-50 Pus cells. Urine culture was positive for E-Coli .

Plain X-ray abdomen was done which was normal.

Ultrasound abdomen revealed markedly enlarged bilateral polycystic kidneys with few cysts in right kidney showing echogenic contents with fluid level suggestive of Infective etiology.

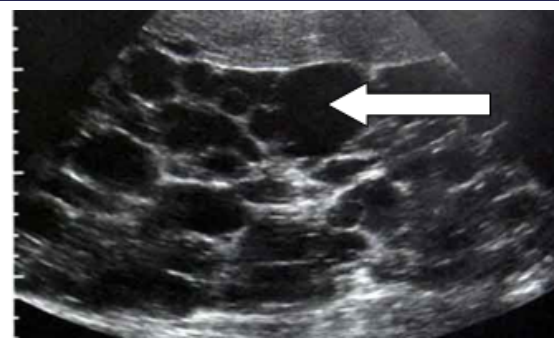

Plain CECT Abdomen suggestive of Enlarged bilateral kidneys with multiple cystic lesions scattered through both the renal parenchyma , largest measuring $4.8 \times 5.2 \mathrm{~cm}$ in upper pole of Right Kidney and $4.6 \times 5.4 \mathrm{~cm}$ in lower pole left kidney with Multiple hyperdensities are seen within cysts of Right kidney.

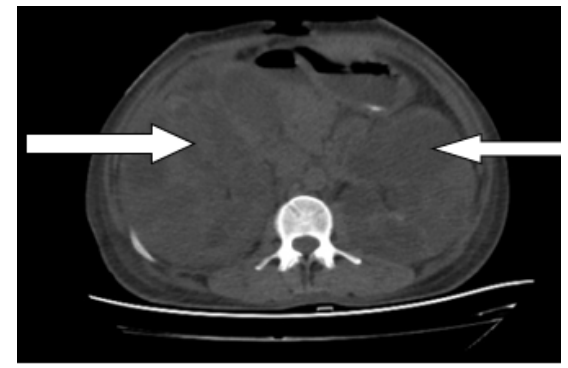

DTPA Scan was done, Suggestive of Suboptimal functioning of both kideys.

Patient was managed conservatively at intensive care unit, responded well to treatment symptomatically, started on Intravenous Antibiotics according to urine culture sensitivity and regular Vital and urine output monitoring was done.

From $5^{\text {th }}$ day of admission patient was having continuous 2,3 fever spikes daily, So The decision of Surgery was taken and was posted for Exploratory Laparotomy. Patient was optmised, and posted for surgery.

Exploratory Laparatomy with Drainage of pus from cysts of Right kidney along with Nephrostomy into 2 larger cysts using Foleys catheter was done, 2 drains were placed in Abdomen and Pelvis respectively.

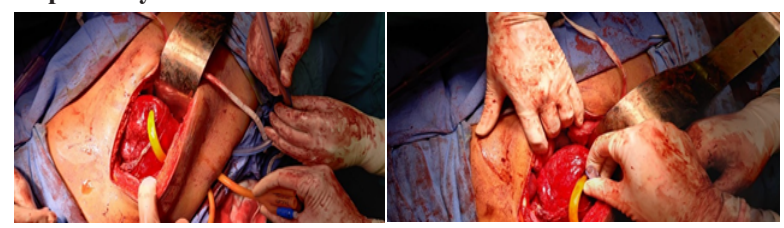




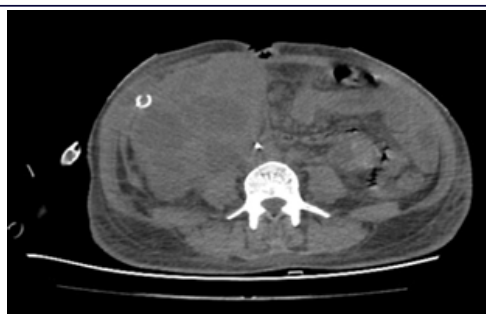

CT scan image with Drain In Situ in Right Polycystic Kidney

The patient was shifted to Intensive Care Unit (ICU) for further management. Culture from the peritoneal pus as well as urine culture were positive for E. coli. Postoperative course of the patient was complicated by severe sepsis with multi organ failure in the form of Adult Respiratory Distress Syndrome, Patient was managed in ICU with ventilator, tracheostomy, and other supportive care, regular drain, input-output and serum creatinine monitering was done

Organ function gradually recovered, Further course in the ward was uneventful and patient was discharged home on the 25 th postoperative day.

\section{DISCUSSION}

Polycystic kidney disease, is a cystic genetic disorder of the kidneys. There are two types of Polycystic Kidney Disease : autosomal dominant polycystic kidney disease (ADPKD) and autosomal recessive polycystic kidney disease (ARPKD)

ADPKD is by far the most common inheritable form of renal cystic disease, with an incidence of approximately 1 in 400 to 1000 live births ${ }^{8}$. It is an important cause of renal failure, accounting for $7 \%$ to $15 \%$ of patients who receive hemodialysis ${ }^{9}$, The trait theoretically has a $100 \%$ penetrance, and, on average, because it is transmitted in an autosomal dominant fashion, $50 \%$ of an affected individual's offspring will likewise be affected. Although a positive family history is one of the major criteria for the diagnosis of ADPKD, $10 \%$ of cases occur sporadically. ${ }^{10}$ A number of associated anomalies are common, including cysts of the liver, pancreas, spleen, and lungs; aneurysms of the circle of Willis, colonic diverticula , aortic aneurysms; and mitral valve prolapse. ${ }^{10}$

There are two major genetic forms of ADPKD caused by mutation in the genes PKD1 and PKD2. ${ }^{7}$ PKD1 has been localized to the short arm of chromosome 16, Mutations in the PKD1 gene account for $85 \%$ of ADPKD cases. ${ }^{11}$ The families of ADPKD patients are being screened by ultrasonography, Large numbers of asymptomatic children with renal cysts are being identified before full-blown disease develops.

\section{Clinical Features}

Typically, signs or symptoms first occur between the ages of 30 and 50 years ${ }^{12}$. These include microscopic and gross hematuria, flank pain, gastrointestinal symptoms, renal colic, and hypertension. Microscopic or gross hematuria is seen in $50 \%$ of patients, and in $19 \%$ to $35 \%$ it is the presenting sign ${ }^{13}$. Because patients with ADPKD have increased renal mass, erythropoietin levels are increased, making anemia unusual even when End Stage Renal Disease is present ${ }^{15}$

Flank Pain is the most common presenting symptom in adults. This results from a number of possible factors: mass effect, bleeding into the cysts, urinary tract infection, and nephrolithiasis. Twenty percent to $30 \%$ of patients with ADPKD develop stones. ${ }^{16}$ As BP screening has become more widespread, hypertension has become a very common form of presentation. ${ }^{17}$ Hypertension is present in roughly $50 \%$ of patients 20 to 35 years old having ADPKD with normal renal function. Almost $100 \%$ of patients with ESRD have hypertension. ${ }^{18}$ The hypertension seems to be renin mediated, secondary to stretching of the intrarenal vessels around cysts, causing distal ischemia. ${ }^{1}$ Hypertension and vascular remodeling secondary to cyst expansion also contribute to progressive renal failure. ${ }^{20}$

\section{Extra Renal Manifestations}

Hepatic cysts, usually identified incidentally by ultrasonography, are the most common extra renal manifestation of ADPKD. They are present in almost all ADPKD patients by the age of 50 years.

Hepatic cysts are usually asymptomatic but can occasionally cause symptoms because of mass effect, complicating infection, or hemorrhage. In rare instances, enlargement of hepatic cysts leads to portal hypertension and bleeding esophageal varices. ${ }^{22}$ Intracranial aneurysms, predominantly aneurysms of the circle of Willis (berry aneurysm) - occur in $10 \%$ to $30 \%$ of patients, and approximately $9 \%$ of these patients die because of subarachnoid hemorrhages..$^{23,24,25,26}$

Cysts may also occur in the seminal vesicles (40\%), arachnoid membrane $(8 \%)$, and pancreas $(5 \%)$. Seminal vesicle cysts rarely cause infertility; however, many of these men may have problems with sperm motility. Arachnoid membrane and pancreatic cyst are typically asymptomatic. Other abnormalities associated with ADPKD are mitral valve prolapse and colonic diverticulosis. ${ }^{27,28,29}$

\section{Evaluation}

it is important to have at least three generations of the patient's family history. History of renal disease, hypertension, and strokes in family. Ultrasonographic diagnostic criteria for individuals at $50 \%$ risk for the disease include at least two unilateral or bilateral cysts in individuals younger than 30 years of age, two cysts in each kidney in individuals 30 to 59 years of age, and four cysts in each kidney in individuals 60 years of age or older ${ }^{30}$.

CT or MRI (or both) may be helpful in some cases and often are superior to ultrasonography for detecting cysts in organs other than the kidney. CT is helpful in making the diagnosis of hemorrhage within a cyst. MRI also may be helpful, particularly in patients with compromised renal function, because no contrast agent is needed.

Current therapy is directed toward lessening the complications of ADPKD and delaying the onset of ESRD. There is no known cure at this time. More than $60 \%$ of patients with ADPKD who do not yet have renal impairment have hypertension ${ }^{31}$

Infection of a cyst within a polycystic kidney is a serious complication of ADPKD, potentially leading to abscess, sepsis, and death. Female preference and enteric organism predominance suggest that these renal infections are acquired to retrograde from the urinary bladder ${ }^{6}$. Clinical presentation is that of peritonitis. Surgery remains the important therapeutic modality after preoperative medical support including broad spectrum parenteral antibiotic coverage, correction of potential electrolyte and coagulation abnormalities, and aggressive intensive care with hemodynamic, pulmonary, and renal replacement support. Elective right nephrectomy was discussed with the patient and relative but they denied for the same.

\section{CONCLUSION}

Abcess in a cyst in polycystic kidney disease is very unusual and potentially serious complication.

Multidisciplinary approach with prompt diagnosis and aggressive surgical intervention with intensive care support is crucial for survival after such complications.

\section{Conflict of Interests}

The authors declare that there is no conflict of interests.

\section{REFERENCES}

[1] K. M. Dell, W. E. Sweeney, and E. D. Avner, "Polycystic kidney disease," in Pediatric Nephrology, E. D. Avner, W. Harmon, P.Niadet, and N. Yoshikawa, Eds., pp. 849-888, Springer. Heidel berg, Germany, 6th edition, 2009.

[2] V. E. Torres, P. C. Harris, and Y. Pirson, "Autosomal dominant polycystic kidney disease," The Lancet, vol. 369, no. 9569, pp.1287-1301, 2007

[3] S. J. Schwab, S. J. Bander, and S. Klahr, "Renal infection in autosomal dominan polycystic kidney disease," The American Journal of Medicine, vol. 82, no. 4, pp 714-718, 1987

[4] P. D. Wilson, "Polycystic Kidney Disease," The New England Journal of Medicine, vol 350 , no. 2, pp. 151-164, 2004

[5] M. Bisceglia, C. A. Galliani, C. Senger, C. Stallone, and A.Sessa, "Renal cystic diseases: a review,"Advances in Anatomic Pathology, vol. 13, no. 1, pp. 26-56, 2006

[6] R. M. deSouza, A. Prachalias, P. Srinivasan, M. O'Doherty, and J. Olsburgh, "Differentiation between infection in kidney and liver cysts in autosomal dominant polycystic kidney disease: use of PET-CT in diagnosis and to guide management," polycystic kidney disease: use of PET-CT in diagnosis and to
Transplantation Proceedings, vol. 41, no. 5, pp. 1942-1945,2009.

[7] Breuning MH, Reeder ST, Brunner H, et al: Improved early diagnoses of adult polycystic kidney disease with flanking DNA markers, Lancet 2:1359, 1987

[8] Grantham JJ: Polycystic kidney disease: hereditary and acquired, Adv Intern Med 38:409, 1993

[9] Grantham JJ: Polycystic renal disease. In Early LE, Gottschalk CW, editors: Strauss and Welt's diseases of the kidney, ed 3, Boston, 1979, Little, Brown, p 1123

[10] Grantham JJ: Polycystic renal disease. In Early LE, Gottschalk CW, editors: Strauss an Welt's diseases of the kidney, ed 3, Boston, 1979, Little, Brown, p 1123

[11] Chakraborty K, McHugh K: Cystic diseases of the kidney in children, Imaging 17:69-75, 2005

[12] Glassberg KI, Stephens FD, Lebowitz RL, et al: Renal dysgenesis and cystic disease o the kidney: a report of the Committee on Terminology, Nomenclature and Classification, 

Section on Urology, American Academy of Pediatrics, J Urol 138:1085, 1987.

[13] Delaney VB, Adler S, Bruns FJ, et al: Autosomal dominant polycystic kidney disease: presentation, complications and progression, Am J Kidney Dis 5:104, 1985.

[15] Gabow PA, Duley I, Johnson AM: Clinical profiles of gross hematuria inautosomal polycystic kidney disease, Am J Kidney Dis 20:140, 1992.

[16] Fick GM, Johnson AM, Gabow PA: Is there evidence for anticipation in autosomaldominant polycystic kidney disease?, Kidney Int 43:1153, 1994.

[17] Zeier M, Geberth S, Ritz E, et al: Adult dominant polycystic kidney disease: clinical Zeier M, Geberth S, Ritz E, et a
problems, Nephron 49:177, 1988

[18] Kelleher CL, McFann KK, Johnson AM, et al: Characteristics of hypertension in young adults with autosomal dominant polycystic kidney disease compared with the general US population, Am J Hypertens 17:1029-1034, 2004

[19] Gabow PA: Autosomal dominant polycystic kidney disease, N Engl J Med 329:332-342, 1993.

[20] Gabow PA, Chapman AB, Johnson AM, et al: Renal structure and hypertensionin autosomal dominant polycystic kidney disease, Kidney Int 38:1177-1180,1990a

[21] Bae KT, Zhu F, Chapman AB, et al: Magnetic resonance imaging evaluation of hepatic cysts in early autosomal-dominant polycystic kidney disease, Clin J Am Soc Nephrol cysts in early autosomal-dominant polycystic kidney disease, Clin J Am Soc Nephrol

[22] Campbell GS, Bick HD, Paulsen EP: Bleeding esophageal varices with polycystic liver: report of three cases, N Engl J Med 259:904, 1958.

[23] Grantham JJ: Polycystic renal disease. In Early LE, Gottschalk CW, editors: Strauss and Welt's diseases of the kidney, ed 3, Boston, 1979, Little, Brown, p 1123.

[24] Hartnett M, Bennett W: External manifestations of cystic renal disease. In Gardner KD Jr, editor: Cystic disease of the kidney, New York, 1976, John Wiley \& Sons, pp 201-219.

[25] Ryu SJ: Intracranial hemorrhage in patients with polycystic kidney disease,Stroke 21:291-294, 1990

[26] Sedman A, Gabow PA: Autosomal dominant polycystic kidney disease, Dialogues Pediatr Urol 7:4, 1984

[27] Hossack KF, Leddy CL, Schrier RW, et al: Incidence of cardiac abnormalities associated with autosomal dominant polycystic kidney disease (ADPKD) [abstract], Am Soc Nephrol 19:46A, 1986

[28] Kupin W, Norris C, Levin NW, et al: Incidence of diverticular disease in patients with polycystic kidney disease (PCKD). Presented at 10th International Congress of Nephrology, London, July 1987.

[29] Scheff RT, Zuckerman G, Harter H, et al: Diverticular disease in patients with chronic renal failure due to polycystic kidney disease, Ann Intern Med 92:202, 1980

[30] Ravine D, Gibson RN, Walker RG, et al: Evaluation of ultra sonographic diagnostic Ravine D, Gibson RN, Walker RG, et al: Evaluation of ultra sonographic diagnos
criteria for autosomal dominant polycystic kidney disease 1, Lancet 343:824, 1994

[31] Gabow PA, Ikle D, Holmes J: Polycystic kidney disease: prospective analysis of non azotemic patients and family members, Ann Intern Med 101(2):238-247, 1984 